\title{
Exploring the biogeochemical sulfur cycle over the past 150 million years
}

ALEXANDRA (SASHA) TURCHYN ${ }^{1}$ AND CHARLOTTE SPRUZEN $^{2}$

${ }^{1}$ University of Cambridge

${ }^{2}$ Cambridge University

Presenting Author: avt25@cam.ac.uk

Over the past 150 million years there has been fundamental reorganisations of biogeochemical cycles at Earth's surface, coupled with a shift in the global carbon cycle from the greenhouse world of the Mesozoic to the icehouse world of the late Cenozoic. Coupled with this change in climate and biogeochemical cycles are changes in major non-traditional isotopes tracking a reorganisation of global elemental cycling at Earth's surface; these changes to nutrient and metal cycles were either driven by the in climate or driven by the same processes that drove changes in climate. Thus the interpretation of changes in Earth's surface environment over this critical time period lies in the understanding of what changes in these elemental cycles portend.

Here we explore changes in one of the major biogeochemical cycles which changes rapidly over this time period, the biogeochemical sulfur cycle. The biogeochemical sulfur cycle comprises an input from rivers and the mantle, and the output into evaporite and sulfide minerals. The sulfur isotopic composition of seawater sulfate has been used widely to reconstruct various fluxes in the biogeochemical sulfur cycle. Over the past 150 million years, the sulfur isotopic composition of seawater sulfate exhibits both shifts in its isotopic composition (often close to major transitions) as well as and overall evolution from towards relatively 'heavier' values. Traditional interpretation of these changes often cite changes in the fluxes of sulfur into and out of Earth's surface environment. However recent work has challenged this interpretation given the systematic spatial differences in the sulfur isotopic composition of pyrite which vary as a function of sedimentation rate, and diagenetic processes within sedimentary environments. We will present a new data compilation of pyrite sulfur isotope composition from drill core and outcrop spanning the last 150 million years which allows us to assess globally the link between depositional environment and the sulfur isotopic composition of pyrite. We use this compilation with a model of the sulfur cycle to explore how local changes in depositional environment may have played a role in shaping changes in the biogeochemical sulfur cycle over this time. 